\title{
Financial Intermediation, Variability and the Development Process
}

\author{
Luis Carranza \\ BBVA Banco Continental \\ José E Galdón-Sánchez \\ London School of Economics and Political Science
}

The Suntory Centre

Suntory and Toyota International Centres for Economics and Related Disciplines

London School of Economics and Political Science Houghton Street

DEDPS 21

March 2000
London WC2A 2AE

Tel: (020) 79556674

\footnotetext{
*We would like to thank Raouf Boucekkine, César Alonso, Juan Carlos Conesa, Jesús Fernandez-Villaverde, Maia Güell, Nobu Kiyotaki, and seminar participants at the University of Minnesota Macroeconomics Workshop, the Universidad Carlos III de Madrid, and XVth Latin American Meeting of the Econometric Society, Santiago de Chile, for very useful comments. José E Galdón-Sánchez thanks DGICYT (grant PB94-0378) and the Fundación Caja de Madrid for financial support. Any views expressed in this paper are those of the authors and not necessarily those of the BBVA Banco Continental. The usual disclaimers apply.
} 


\begin{abstract}
In this paper we build a model of financial intermediation that explains the GDP variability pattern of an economy during the development process. In our model, per capita output is more volatile in middle-income economies than in both low and highincome economies. We show that, if the model economy is in the early or in the mature stages of development, multiple equilibria arise. Moreover, we find that in economies with imperfect credit markets, per capita output volatility tneds to be higher than in economies with perfect or non-existent credit markets.
\end{abstract}

Keywords: Externalities, market imperfections, growth, multiple equilibria, sunspot equilibrium.

JEL Nos.: E00 O11, O16, O40.

(C) Luis Carranza and José E Galdón-Sánchez. All rights reserved. Short sections of text, not to exceed two paragraphs, may be quoted without explicit permission provided that full credit, including (c) notice, is given to the source.

Contact address: José E Galdón-Sánchez, STICERD, London School of Economics and Political Science, Houghton Street, London WC2A 2AE, UK. Email: j.e.galdon@lse.ac.uk 


\section{Introduction}

In this paper we investigate the GDP variability pattern during the development process. We find evidence that per capita GDP variability is low in both low and high income economies, yet high in middle-income ones. We provide a theoretical model of financial intermediation that explains the high variability of per capita GDP displayed by middle-income countries, relative to the low variability of per capita GDP shown by both low and high income economies.

While there is a substantial literature on the role that financial intermediation has over growth (see the excellent survey by Levine, 1997), little attention has been paid to its effect on the dynamics of GDP during the development process. Our model highlights the link between the variability of output and the degree of development of the financial sector. We find that in the case of either economies with perfect credit markets or economies in which the credit markets are non-existent, the equilibrium is unique. However, when the credit market exists but is imperfect, there can be more than one equilibrium. In the latter case, the multiplicity arises in the middle stages of development.

In order to reach our goal, we build a model of financial intermediation with borrowing constraints and externalities that generates multiple equilibria, and in which agents rely on a sunspot to coordinate their actions at intermediate stages of development. This sunspot is a random variable with its own variance, which drives the variance in the model. The main mechanism is that the more agents have access to credit, the larger is the advanced technology sector in the economy and the higher are wages. Higher wages relax borrowing constraints for agents who want to invest in the more advanced sector, and that generates growth. At the same time, higher wages do not decrease profits and discourage investment, because the size of the advanced sector is itself a productive externality in that sector. Then, since agents must decide 
in advance whether to invest in the advanced sector, the return to their investment depends on how many people today choose to go into the advanced sector. This is the source of the coordination failure and the need for the sunspot to determine the equilibrium. Finally, the multiplicity arises because the number of agents who are credit constrained depends on the number of agents who invest, and if the constraint is not there, the multiplicity disappears, because only resource constraints matter.

Our model is a two-periods overlapping generations model. In the first period, the agents are heterogeneous in their ability to work and, therefore, in their endowments. In the second period, they become entrepreneurs and have to decide whether to use an advanced technology or a subsistence technology. The use of the advanced technology entails a fixed cost, while the use of the subsistence technology does not. The agents who want to become entrepreneurs in the advanced sector but do not have enough resources to pay the entry cost can borrow these resources.

In our model, we also assume that lenders cannot force borrowers to repay their debts unless the debts are secured, and that the returns from investment are only partially collateralizable. Given this credit market imperfection, the externality in the productive sector will be reflected in the financial sector: the larger the fraction of people in the advanced technology sector, the larger the fraction of people that will have access to the credit market. The reason is that the borrowing constraint is relaxed as the returns in the advanced technology increase. This is the source of multiple equilibria in the model which arise in the middle stage of the development process. On the contrary, in early and mature stages of development, the multiplicity does not appear.

The paper also explores the relationship between the borrowing constraints faced by individuals and per capita GDP variability. We find that, in economies where individuals are not borrowing constrained, or for those in which the credit market 
is non-existent, the equilibrium is unique. However, when the credit market exists but is imperfect, i.e. when there are borrowing constraints, there can be more than one equilibrium. In this case, we find that multiplicity of equilibria arises in middle stages of development.

It is worthwhile to note that, if the credit market does not exist or if there are not borrowing constraints, there is no interaction between the externality in the productive sector and the borrowing constraint. In the first case, only the fraction of people with wealth greater than the cost of entry will become entrepreneurs. In the second case, since there are no borrowing constraints, all the resources are used to finance the payment of the entry cost for those who want to use the advanced technology. Moreover, the interest rate will be such that the agents are indifferent between using the advanced or the subsistence technology.

In an economy with borrowing constraints, the income distribution plays a very important role in determining the equilibrium. In that sense, this paper follows the line of work of Galor and Zeira (1993), Banerje and Newman (1994), Carranza (1995) and Aghion et al. (1998), in which income distribution is an important instrument to explain the economy's behavior in the development process. In our model, the income distribution and the externality effect determine the number of equilibria and the stage at which the multiplicity of equilibria arises and when it vanishes.

In order to deal with the presence of multiplicity of equilibria, we assume the existence of a sunspot process. In our model, this sunspot process coordinates the actions of the agents. In that respect, this paper is related to Cooper and Ejarque (1995), Sorger (1994), and Spear (1991). The paper by Cooper and Ejarque (1995) presents a model in which the indeterminacy of equilibrium is resolved by a sunspot process. There, the multiplicity of equilibria arises from the existence of non-convexities in the intermediation process. In Sorger (1994), a one-sector neoclassical growth model 
with borrowing constraints and heterogeneous agents is used to show that there can exist sunspot equilibria. Spear (1991) analyzes a dynamic model of pure capital accumulation to show the existence of sunspot equilibria in a way that prevents the model to collapse to an overlapping generations equivalent.

Therefore, in our model, there are two central elements: externalities and market imperfections, and both are necessary conditions for the existence of multiple equilibria. The way in which the sunspot mechanism affects the equilibrium will depend on both the degree of imperfection and the size of the economy. It is also important to note that, in our model, the set of equilibria changes over time. It is not constant. Moreover, the number of equilibria depends on the size of the economy.

Finally, the paper shows that the introduction of a new "technology", a financial technology in our case, could affect positively the growth rate in the economy and, at the same time, be a source of higher variability if the markets are not complete. The Mexican crisis in a globalized market environment illustrates this point.

The paper is organized as follows. In Section 2, we analyze the empirical evidence. Section 3 presents the environment: a description of the model and a discussion on the problem of occupational choice. The analysis of the economy's labor and credit markets, and the definition of equilibrium is performed in Section 4. Section 5 explains the dynamics of the economy: the relationship between the level and variability of GDP per capita in an economy with imperfect credit markets, an analysis of the behavior of wages, interest rates, and entrepreneurial choice during the development process, and a discussion of the perfect credit market and non-credit market cases. Finally, the conclusions are presented in Section 6. 


\section{Empirical Evidence}

In this section, we argue that poor and rich countries exhibit lower per capita GDP variability than middle-income countries. Poor countries tend to grow slowly because rapid growth is simply not possible. When a poor country grows long enough to achieve a certain minimum income level, rapid growth becomes a possibility but not a certainty. During this stage, the poor country may continue on its slow growth path or it may "take-off" and grow rapidly. On the other hand, it is possible that a rapidly growing country may suddenly "reverse course" and begin declining. But, if rapid growth is sustained for a while, the once-poor country passes a second income threshold beyond which economic decline is no longer a possibility.

First, since we do not want to impose any functional form to our data, we do a nonparametric regression with kernel smoothing, by which we do not impose any functional restriction but smoothness (see Härdle, 1990). In order to do this, we use the Nadaraya-Watson window and Silverman's rule of thumb. To make it comparable with other empirical evidence such as Acemoglu and Zilibotti (1997), we take the data source in Summers and Heston $(1991)^{1}$ for the period 1960-1985. Following Parente and Prescott (1993), OPEC members, countries with less than one million citizens and countries without a complete data set were dropped from the data. We first calculate the linear trend over the logarithm of per capita GDP for each country. ${ }^{2}$

\footnotetext{
${ }^{1}$ For our purposes, it would be desirable to have growth series of 150 or 200 years for developed countries that were previously underdeveloped. That is, the span period should cover from underdevelopment to development. The problem is that there are very few (if any) countries, which were not already developed 150 years ago, that have series of GDP that long. However, we could get the experiences of Japan and South Korea that, in few years, evolved from underdevelopment to development. But this evidence would only show one or two trajectories of growth of all the multiple possibilities that there are. Just because we have multiple equilibria, we cannot have only one or two trajectories, and this evidence would not suit our purposes. Given that, we use the only evidence available: cross-country data for a group of countries that differ in their stages of development. And we calculate their variability for the period available.

${ }^{2}$ We also calculated a variability index for different groups of countries. The data source we used is the one in Summers and Heston (1991) for the period 1960-1990. Again, OPEC members, countries with less than one million citizens and countries without a complete data set were dropped
} 
In addition to this trend, we introduce dummies for eight countries. The dummies are associated with outstanding events that occurred in those countries in particular years (years of independence; civil, ethnic or other kind of wars; natural catastrophes; magnicides or coups d'état). All the dummies that we include are significant at the 5 percent level. That is, for a dummy to be included, such dummy, reporting if an event of the nature described above took place, must be significant at the 5 percent level. ${ }^{3}$ In any case, there are only 25 dummies in a set of 2,574 observations (less than 0.9 percent). ${ }^{4}$ Then, we calculate the conditional expectation of the absolute value of the deviation from the trend. The results are reported in Figure 1.

[Figure 1 here]

Since these dummies are concentrated in low-income countries, one could argue that their presence could bring down the left hand side of our regression. Therefore, introducing dummies in the middle of the distribution would bring down the U-inverted shape as well. This is not true for two reasons. The first one is statistical. In the left hand side of the income distribution, the deviations are generally small except for very few outliers in the distribution. In the middle, most of the deviations

from the data. We first regressed per capita GDP levels in dollars against time for each country, calculating its trend afterwards. The results still hold when the series are filtered with the HodrickPrescott filter. The statistic we used consists of the sum of each country's squared per capita GDP deviations from its trend, divided by the average per capita GDP. These statistics yield variability indices for each one of the countries in our data set. Finally, countries are decomposed in four groups by income levels $(\leq \$ 999 ; \$ 1,000-\$ 4,999 ; \$ 5,000-\$ 9,999 ;$ and $\geq \$ 10,000)$ and an average variability index for each group of countries is obtained. Similar results are obtained if we calculate standard deviations of growth rates. The result is a very similar shape to those that will appear next in Figures 1 and 2.

${ }^{3}$ Note that there are some events of the nature described above that will not be reported with a dummy because those dummies were not found significant. For example, the coups d'état in Argentina (1976) and Chile (1973), among others.

${ }^{4}$ The 25 dummies have the following characteristics. By countries: nine of them belong to Chad; four to Burundi; two to Lesotho, Mali and Rwanda; and one to Argentina, Burkina Faso, Greece, Mexico, Myanmar (Burma) and Togo. By years: 11 are on the 60's (four in 1960 and two in 1965), nine on the 70's (two in 1970, none in 1975), and five on the 80's (none in 1980 and one in 1985). By events: 12 are related with civil, ethnic or other kind of wars; six with the independence year; four with coups d'état; two with magnicides; and one with a natural catastrophe. For more details see Enciclopædia Britannica (1999). 
are of large magnitude, so that an equivalent number of dummies would not substantially affect this inverted-U shape. The second reason has to do with History. Most of the dummies introduced are due to the independence of an African country and civil or other kind of wars (17 of the 22 dummies). The independence of a country would usually have brought turbulences and social unrest that are idiosyncratic to that country. Moreover, in the countries considered, the civil wars were usually accompanied by genocide or an ethnic purge. In any case, all dummies are documented and significant.

In addition, we also estimated second-order polynomials in the log of real GDP per capita for the absolute percentage deviation from the GDP trend, for six different years. We do not perform a nonparametric kernel regression here since we have few observations in each one of those exercises. In all the cases, the quadratic term was strongly significant, yielding evidence against the restricted linear model. In Figure 2, we have plotted the predicted values from the regressions and their 95 percent confidence bands for each year. From this figure, the inverted U-shape becomes apparent, although the high variability of the data gives evidence of important unobserved heterogeneity that cannot be explained by the quadratic specification (and much less by the restricted linear specification).

[Figure 2 here]

A version of Figures 1 and 2 has already been documented by Chari et al. (1996) and Quah (1993). Both papers construct a mobility matrix whose $(j, k)$ entries represent the probabilities that an economy in a bin $j$ transits to a state $k$. Those matrices show that countries in the middle income groups tend to move up or down more frequently than countries in the extremes. Thus, very poor countries tend to stay very poor and the rich countries tend to stay rich, but there are much more dynamics in the middle of the distribution. Quah also speaks of a closely connected issue: the 
emergence of a twin-peaks distribution. This bimodal shape can be interpreted as evidence of a higher level of variability in middle income countries. A similar approach is followed by McGrattan and Schmitz (1998).

This evidence is somehow at odds with a part of the literature. Some exponents of this literature are Ramey and Ramey (1995), Mendoza (1995) and Acemoglu and Zilibotti (1997). In particular, the last of these papers documents a monotone decreasing relationship between variability and per capita income level, building an interesting model that accounts for that evidence linking the degree of market incompleteness to capital accumulation and growth.

There are several possible explanations for the different interpretation of the evidence. First, with our kernel estimation, we do not impose any functional form but smoothness. In their paper, however, Acemoglu and Zilibotti impose a linear functional form when calculating their Figure 1. In fact, when we impose a linear functional form, we obtain a significantly negative slope (with a value of -0.0055 , significant at the 0.01 percent), which is plotted together with the data in Figure 3. Nevertheless, the inclusion of an additional quadratic term restored the inverted-U shape again and improved the adjusted $R^{2}$ significantly (from 0.01 to 0.04 ). This exercise illustrates that the monotone negative slope showed by their figure is just a result of the functional form chosen.

[Figure 3 here]

Second, the independent variable in their regression is GDP per capita in 1960, but countries move along the sample period raising an identification problem. Indeed, their dependent variable could be picking up two things. On the one hand, a country which stays poor during the whole period (and then with low variance over time) and, on the other, the case of a country that has become rich (and whose movement along the curve has increased its variability level). A regression in which only 1960 GDP 
is used cannot distinguish between these polar dynamics, while our approach takes account of the evolution of per capita GDP over time, keeping as much information as possible.

Finally, the potential presence of an outlier should not require the elimination of the whole set of observations for a particular country from the sample. We control for outliers with the help of a dummy variable, preserving the maximum amount of information..$^{5}$

\section{The Environment}

In this section, we first describe the model and then discuss the problem of occupational choice.

\subsection{The Model}

The model is a two-period overlapping generations model. At each date $t$, a continuum of agents of measure one is born. Each agent is endowed with one unit of labor at each period. In the first period, the individuals can only be workers. They have some capacity (or ability) $c$ with support on the interval $[\alpha, \beta]$, where $\alpha$ and $\beta$ are both positive numbers, a continuous probability distribution function $h(c)$, and a continuous cumulative distribution function $H(c)$. In the second period, the agents can only be managers either in the advanced or the subsistence sector (and managers are all the same by technology managed). ${ }^{6}$ At $t=0$, the initial 'old' are endowed with $c v_{0}$, where $c$ is the same random variable as before, and $v_{0}$ is a non-negative number.

The agents born at time $t$ receive utility only from consumption at $t+1$. This is

\footnotetext{
${ }^{5}$ All regression results from which the former figures were drawn are available upon request.

${ }^{6}$ This is just a simplifiying assumption. If we allow the agents in the second period the possibility to be either workers or entrepreneurs, we complicate the model without altering our result.
} 
an innocuous ${ }^{7}$ assumption that simplifies the algebra. Each agent can choose between managing an advanced or a subsistence technology. If the agent chooses to manage the subsistence technology, she will have access to the following production function:

$$
g(l)
$$

with $g_{l}>0$ and $g_{l l}<0$. Where $l$ stands for labor input, $g_{l}$ is the first derivative with respect to $l$, and $g_{l l}$ is the second derivative with respect to $l$, for all $l>0$.

If the agent wants to manage the advanced technology, she must pay an entry $\operatorname{cost} \phi$ at the end of the initial period. That is, the agent must commit herself to this technology. In the second period, she will have access to a production function of the form:

$$
f(l, \lambda)
$$

with $f_{l}>0, f_{l l}<0, f_{\lambda}>0, f_{\lambda \lambda}<0, f_{l \lambda}>0$ and $f_{l l}>g_{l l}$, for all $l>0$. Here $\lambda$ stands for the fraction of people who choose to be managers in the advanced technology sector. That is, the more managers in the advanced technology sector, the higher the potential returns in that sector. Notice that the production function allows for the existence of an externality. This production functional form can be rationalized by the existence of learning-by-doing spillovers in the use of technology or by the existence of technology as a by product of production (see Arrow, 1962, and Romer, 1986). Moreover, the production function does not depend on capital in the advanced or the subsistence sectors. The results would be exactly the same if capital were included. What it is really important is that the production functions have decreasing returns to scale in labor $^{8}$ since the managerial ability is also a productive factor that needs to be considered.

\footnotetext{
${ }^{7}$ Innocuous for our multiple equlibria result.

${ }^{8}$ And capital if it were included.
} 
Two assumptions about the parameters of the model must be made:

Assumption 1.- Even if nobody is using the advanced technology, the net return to this technology is higher than the return of the subsistence technology. That is:

$$
f(l, 0)-\phi>g(l), \forall l>0
$$

Assumption 2.- The entry cost belongs to the interval $(\alpha, \beta)$. More specifically:

$$
\alpha<\phi<\beta
$$

There also exists a storage technology. By using this technology, the agents can transform date $t$ goods into date $t+1$ goods at a one-to-one rate.

The individual can borrow resources to pay the entry cost, with the obligation to repay the loan in the next period. However, since credit markets are imperfect, there exists an enforcement problem. The lenders can not force the borrowers to repay the debt, but they can seize a fraction $\theta$ of the borrowers' managerial income. Also, it is assumed that there exists perfect information about the initial wealth of each agent.

In this model, the decisions are sequential. Agents born in period $t$ work for managers who were born in period $t-1$. They are paid according to their ability. At the end of period $t$, they make their financial decisions (lend, borrow or invest in the storage technology) and decide whether or not to pay the entry cost. At period $t+1$, those who paid the entry cost can manage the advance technology, otherwise they manage the subsistence technology. Managers will hire labor at a competitive wage and, at the end of the period, will execute the financial obligations and consume whatever is left.

Notice that the decision to pay the entry cost must be taken at the end of the period, when the number of entrepreneurs in the advanced sector is unknown. In order to solve this problem, we assume the existence of a sunspot process that coordinates 
the actions of the agents. ${ }^{9}$ That is, the sunspot is generated from a correlated device from which the agents receive signals. The decisions made by the agents are functions of the received signal (observed sunspot). In order to incorporate the sunspot into the model, let us define $\omega_{t}$ as the state of the economy at time $t$; and $\Sigma_{t}$ as the set of possible sunspots at time $t$, where in fact this set is a function of the state of the economy, i.e. $\Sigma_{t}=\Sigma\left(\omega_{t}\right)$. Also, let $\sigma_{t}$ be an element of $\Sigma_{t}$. For completeness, let us define a probability distribution of $\Sigma_{t}$ denoted $\Psi_{t}$, i.e. $\Psi_{t} \in \Psi\left(\Sigma_{t}\right)$, where $\Psi(A)$ denotes the set of probability distributions over the set $A$.

\subsection{Optimal Behavior}

In this subsection, we are going to analyze the optimal decisions of an agent type $c$ born at period $t$. This can be done solving the model backwards. Let us start with the assumption that the agent has paid the entry cost at time $t$. This means she is a manager in the advanced sector, and she will try to maximize her managerial income taking as given the wage rate, $v_{t+1}$. That is:

$$
\Pi_{a}\left(v_{t+1}, \lambda_{t+1}\right)=\max _{l_{a}}\left\{f\left(l_{a}, \lambda_{t+1}\right)-v_{t+1} l_{a}\right\}
$$

where $l_{a}\left(v_{t+1}, \lambda_{t+1}\right)$ is labor in the advanced technology sector and the solution to this problem. Notice that, at this stage, the fraction of total managers in the advanced sector is known.

If the agent has not paid the entry cost, she becomes a manager in the subsistence sector. The income from being a manager at the subsistence sector is:

$$
\Pi_{s}\left(v_{t+1}\right)=\max _{l_{s}}\left\{g\left(l_{s}\right)-v_{t+1} l_{s}\right\}
$$

\footnotetext{
${ }^{9}$ Here we follow the same idea as Cooper and Ejarque (1995). Their model, as ours, is inspired in the idea of Correlated Equilibrium (see Auman, 1987) as a generalization of Nash Equilibrium in which agent's actions are based on extrinsic noise.
} 
where $l_{s}\left(v_{t+1}\right)$ is labor in the subsistence technology sector and the solution to (6). Notice that in equilibrium $v$ will be a function of $\lambda$; so $l_{s}$ and $\Pi_{s}$ will also be functions of $\lambda$. Since $v_{t+1}$ depends on the fractions of managers $\lambda_{t+1}$, which in turns depends on the observed signal $\sigma$, we should be able to express the agent's income as a function solely of $\lambda(\sigma)$. This is done below.

At the end of period $t$, an agent type $c$ has wealth $c v_{t}$. At that time, she must choose whether or not to pay the entry cost and the financial contracts. Notice that, at this point, $\lambda_{t+1}$ is unknown, but the agents observe a signal (sunspot) $\sigma$, and take a decision.

Given $\sigma$, the agents will pay the entry cost only if two conditions are satisfied:

$$
\begin{gathered}
\Pi_{a}(\lambda(\sigma))-r_{t, t+1} \phi \geq \Pi_{s}(\lambda(\sigma)) \\
\theta \Pi_{a}(\lambda(\sigma)) \geq r_{t, t+1}\left(\phi-c v_{t}\right)
\end{gathered}
$$

where $r_{t, t+1}$ is the interest factor for loans made at period $t$ and repaid at period $t+1$. Interpreting equation (7) is trivial. It just tells us that the individual will pay the entry cost if the net return of doing this is higher than its opportunity cost. Equation (8) tells us about the borrowing constraint. If the amount of resources that the agent must repay at period $t+1$ is greater than the fraction $\theta$ of her final income, the agent will not receive credit because she will have an incentive to default.

Definition 1 . For an agent type $c$, and sunspot $\sigma$, let us define the indicator function $\Phi\left(c, \lambda(\sigma), v_{t}, v_{t+1}, r_{t, t+1}\right)$ such that:

$$
\begin{aligned}
\Phi\left(c, \lambda(\sigma), v_{t}, v_{t+1}, r_{t, t+1}\right) & =1 \text { if }(7) \text { and }(8) \text { are satisfied } \\
& =0 \text { otherwise }
\end{aligned}
$$


Let us now characterize the borrowing constraint of this economy. Using equation (8), we can have and idea of the extent of credit rationing in this economy. Solving equation (8) with equality, we get:

$$
c_{R}\left(\lambda(\sigma), v_{t}, r_{t, t+1}\right)=\frac{\phi-\frac{\theta \Pi_{a}(\lambda(\sigma))}{r_{t, t+1}}}{v_{t}}
$$

Therefore, an agent with initial ability $c$ will receive credit if $c \geq c_{R}\left(\lambda(\sigma), v_{t}, r_{t, t+1}\right)$ and she will be denied credit if $c<c_{R}\left(\lambda(\sigma), v_{t}, r_{t, t+1}\right)$. Now, we can see how the externality in the productive sector is reflected in the financial sector. The equation $c_{R}\left(\lambda(\sigma), v_{t}, r_{t, t+1}\right)$ is decreasing in $\lambda$, that is, the larger the fraction of population using the advanced technology, the more people will have access to the credit market. Also, note that $c_{R}\left(\lambda(\sigma), v_{t}, r_{t, t+1}\right)$ depends negatively on $v_{t}$. A higher wage implies a lower critical level, so the fraction of people who are credit constrained is smaller. In Proposition $1, c_{R}\left(\lambda(\sigma), v_{t}, r_{t, t+1}\right)$ will be completely characterized.

Proposition 1 . Let $c_{R}:[0,1] \times R \times[1, \infty) \rightarrow R$ be a function defined by (10). Then:

(i) $c_{R}(\cdot)$ is continuous in all its arguments,

(ii) $c_{R}(\cdot)$ is increasing in $r$, and

(iii) $c_{R}(\cdot)$ is decreasing in $\lambda$ and $v$.

Proof. [See Appendix].

\section{Markets' Description and Equilibrium}

Before we define the equilibrium for this economy, we will analyze the labor and credit markets, paying special attention to how the problem of multiple equilibria arises in this environment. 


\subsection{Labor Market}

The labor market at period $t+1$ is composed of managers (agents born at period $t$ ) who demand labor and workers (agents born at $t+1$ ) who supply labor. The total labor supply of the new generation is given by:

$$
\int_{\alpha}^{\beta} c d H(c)=\delta
$$

where $\delta$ is the total "effective" labor force. ${ }^{10}$

Given the signal $\sigma$ at time $t$, some individuals will decide to become managers in the advanced sector paying the entry cost. Those who did not pay the fixed cost at time $t$ can either be workers or managers in the subsistence sector. The managers' labor demands in the advanced and the subsistence sectors are given by equations (12) and (13) respectively:

$$
\begin{gathered}
\int_{\alpha}^{\beta} \Phi\left(c, \lambda(\sigma), v_{t}, v_{t+1}, r_{t, t+1}\right) l_{a}(\lambda(\sigma)) d H(c)=\lambda(\sigma) l_{a}(\lambda(\sigma)) \\
\int_{\alpha}^{\beta}\left(1-\Phi\left(c, \lambda(\sigma), v_{t}, v_{t+1}, r_{t, t+1}\right)\right) l_{s}(\lambda(\sigma)) d H(c)=(1-\lambda(\sigma)) l_{s}(\lambda(\sigma))
\end{gathered}
$$

The equilibrium wage in this market, $v(\lambda)$ is given by:

$$
\lambda(\sigma) l_{a}(\lambda(\sigma))+(1-\lambda(\sigma)) l_{s}(\lambda(\sigma))=\delta
$$

As we pointed out in Subsection 3.2, the equilibrium wage in the labor market will be a function of the measure of entrepreneurs in the advanced sector. We can use equations (5), (6) and (14) to solve for $v(\lambda), l_{a}(\lambda)$ and $l_{s}(\lambda)$. We found that $v(\lambda)$ is strictly increasing in $\lambda$, and that $l_{s}(\lambda)$ is decreasing in $\lambda$. Moreover, if the

\footnotetext{
${ }^{10}$ This is due to the fact that abilities differ among the agents.
} 
externality effect is strong enough, then $l_{a}$ will also be increasing. A higher fraction of people using the advanced technology will imply an increment in the total labor demand and consequently a higher level of wages. The next proposition formalizes this statement.

\section{Proposition 2 .}

(i) $v(\lambda)$ is increasing in $\lambda$, and

(ii) $l_{s}(\lambda)$ is decreasing in $\lambda$.

Proof. [See Appendix].

\subsection{Credit Market}

Since this is an overlapping generations model, there cannot be debt contracts between different generations. All credit transactions must be realized among members of the same generation. At each period $t$, only the members of generation $t$ are engaged in financial transactions. Also, notice that the interest rate is bounded below by the storage technology gross return, i.e. $r_{t, t+1} \geq 1, \forall t$.

The total funds, at any point in time, are given by the total amount of resources in the economy, $\delta v_{t}$. Agents who want to be managers in the advanced technology sector at $t+1$ must pay the entry cost, $\phi$, at time $t$. They can do this using internal plus external funds. Therefore, the total demand for funds in this economy is:

$$
\phi \int_{\alpha}^{\beta} \Phi\left(c, \lambda(\sigma), v_{t}, v_{t+1}, r_{t, t+1}\right) d H(c)=\phi \lambda(\sigma)
$$

Then, the equilibrium interest rate is given by:

$$
\phi \lambda_{t+1}\left(\sigma_{t}\right) \leq \delta v_{t} \text { with }=\text { if } r_{t, t+1} \geq 1
$$

In order to clarify equation (16), note that equation (15) is a fixed point problem with, possibly, more than one solution. Notice that, when $\phi \lambda_{t+1}<\delta v_{t}$, that is, when 
the fraction of entrepreneurs is less than the fraction of projects that can be financed in the economy, the interest rate factor will be equal to one. We can rule out some solutions of (15). In particular, we can rule out any $\lambda>\lambda_{\max }$, where $\lambda_{\max }$ is the maximum measure of people that can be managers at any time:

$$
\lambda_{\max , t}=\min \left(\frac{\delta v_{t}}{\phi}, 1\right)
$$

The total fraction of entrepreneurs is restricted by the resources in the economy, so it can not be greater than the funds available per project at any time, or the actual size of population. An equilibrium in which the resources are used in an efficient way, that is, to finance the maximum number of projects, can exist if and only if:

$$
\lambda_{\max } \leq 1-H\left(c_{R}\left(\lambda_{\max }, v, 1\right)\right)
$$

If condition (18) is satisfied, there exists an excess of demand in the credit market. By continuity of $c_{R}(\cdot)$ and $H(\cdot)$, we can find an interest rate, $r\left(\lambda_{\max }, v\right)$, that will clear the market. The equilibrium will be reached if, at $r\left(\lambda_{\max }, v\right)$, the agents are indifferent between being a manager in the advanced and the subsistence technology; or because the tightening of the borrowing constraint will squeeze enough people out of the credit market, i.e.

$$
r\left(\lambda_{\max }, v\right)=\min \left\{r_{1}\left(\lambda_{\max }, v\right), r_{2}\left(\lambda_{\max }, v\right)\right\}
$$

where $r_{1}\left(\lambda_{\max }, v\right)$ and $r_{2}\left(\lambda_{\max }, v\right)$ solve the following equations:

$$
\begin{gathered}
\Pi_{a}\left(\lambda_{\max }\right)-\phi r_{1}\left(\lambda_{\max }, v\right)=\Pi_{s}\left(\lambda_{\max }\right) \\
\lambda_{\max }=1-H\left(c_{R}\left(\lambda_{\max }, v, r_{2}\left(\lambda_{\max }, v\right)\right)\right)
\end{gathered}
$$


Note that equation (18) holds when the economy has abundant financial resources. Before analyzing the evolution of the economy, let us define the equilibrium properly.

\subsection{Equilibrium}

A sunspot-correlated equilibrium is a sequence of prices $\left\{r_{t, t+1}, v_{t}\right\}$, fractions of managers $\left\{\lambda_{t}\left(\sigma_{t-1}\right)\right\}$, and labor demands $\left\{l_{a t}\left(\lambda_{t}\left(\sigma_{t-1}\right)\right), l_{s t}\left(\lambda_{t}\left(\sigma_{t-1}\right)\right)\right\}$, all of which are functions of the history of sunspots, such that:

\section{Optimality}

- Given $\sigma_{t-1}, \lambda_{t}\left(\sigma_{t-1}\right), v_{t-1}, v_{t}$, and $r_{t-1, t} ; l_{a t .}(\cdot)$ and $l_{s t}(\cdot)$ solve problems (5) and (6) respectively.

- Given $\sigma_{t-1}, \lambda_{t}\left(\sigma_{t-1}\right), v_{t-1}, v_{t}$, and $r_{t-1, t}$; an individual type $c$ chooses $\Phi(\cdot)$ to satisfy (7) and (8).

\section{Market Clearing}

- Given $\sigma_{t}, \lambda_{t+1}\left(\sigma_{t}\right)$ and $v_{t} ; r_{t, t+1}$ and $v_{t+1}$ clear the credit and the labor markets.

\section{Consistency}

- Given $\sigma_{t}, v_{t}, v_{t+1}$ and $r_{t, t+1}$ :

$$
\int_{\alpha}^{\beta} \Phi_{t}\left(c, \lambda_{t+1}\left(\sigma_{t}\right), v_{t}, v_{t+1}, r_{t, t+1}\right) d H(c)=\lambda_{t+1}\left(\sigma_{t}\right)
$$

\section{The Dynamics of the Model}

The purpose of this section is to carefully explain the dynamics of our model. In order to do this, we first study the relationship between the level and variability of GDP per capita in an economy with imperfect credit markets. Then we carry out an analysis of the behavior of wages, interest rates, and entrepreneurial choice during the development process. Finally, we discuss the perfect credit market and non credit market cases. 


\subsection{Multiple Equilibria in the Development Process}

In this subsection, we study the process of economic development. We find that, in the early stages of development, there is only one equilibrium. The multiplicity of equilibria arises when the economy reaches a minimum level of wealth that allows a non-trivial fraction of people to obtain credit. Once the economy is at this stage, due to the existence of an externality in the productive sector, there will be more than one equilibrium. As we will prove in the next section, this problem does not arise if the credit market is perfect or if it does not exist. The reason for this result is that, in these cases, the connection between the externality effect and the credit market is broken. The multiplicity of equilibria will remain until the economy reaches a new threshold level. At that point, some individuals will have access to the credit market even though the measure of entrepreneurs is zero.

Before analyzing the development process, let us define the function $\gamma(\cdot)$ by:

$$
\gamma(\lambda, v, r)=1-H\left(c_{R}(\lambda, v, r)\right)
$$

The next proposition characterizes this function $\gamma(\cdot)$. Note that the slope of this function with respect to $\lambda$ is always positive, but the magnitude of the slope will depend on the sign of the first derivative of $h(c)$ with respect to $c, h_{c}(c)$, and the relative strength of the externality effect.

Proposition 3 . The function $\gamma(\cdot)$ defined in (22) is:

(i) a continuous function of $\lambda$, $v$ and $r$,

(ii) increasing in $\lambda$ and $v$,

(iii) decreasing in $r$, and

(iv) $\gamma_{\lambda}>0$.

Proof. [See Appendix]. 
Next, we will analyze the equilibrium along the development process for an economy that satisfies the following assumptions:

Assumption 3.- $h(c)$ is uniform.

Assumption 4.- There is an externality effect: $f_{\lambda}>B$, for some $B$ and $\lambda$ close to zero.

Assumption 3 is for simplicity. Moreover, it can be shown that if $h$ is uniform and $\Pi_{a}$ is a concave function of $\lambda$, then $\gamma_{\lambda \lambda}<0$.

To find an equilibrium, we need to find the fixed point of equation (15). We can find a set of wages close to zero such that, even though the fraction of entrepreneurs is equal to one, there is no agent who can have access to the credit market. No matter how big the externality is, we can always have wages close enough to zero such that the critical level of ability to get credit is greater than $\beta$. In this situation, there exists a unique equilibrium in this economy. This equilibrium is given by $\lambda=0$.

For a higher wage, and given a strong externality effect, we can have a situation in which a positive fraction of entrepreneurs can overcome the credit constraint just because the same fraction of people becomes managers in the advanced technology sector. This will be an equilibrium if and only if the resources of the economy are big enough to finance this measure of entrepreneurs. If this is not the case, the economy has still a unique equilibrium. As the economy grows, we find two positive measures of entrepreneurs that could be considered as equilibria. We will show that, at some point, the resources in the economy will be big enough to finance the lowest of these fractions of managers. At that point, we have two equilibria. One is given by the lowest of these positive measures, the other given by $\lambda=0$. Remember that even if the measure of entrepreneurs is zero, nobody can overcome the borrowing constraint.

From this period, the number of equilibria will increase to three, the first two 
being as the ones obtained before, and the third one given by the resources in the economy: $\lambda_{t}=\frac{\delta v_{t}}{\phi}$. In this situation, such measure of entrepreneurs implies that a much bigger fraction of people can have access to the credit market. Since there are not enough resources in the economy to finance all these projects, the interest rate must rise to clear this excess demand. We will prove that, for the relevant range of wages, the highest fixed point of this problem will always be above the economy's resources. This situation will persist until the economy reaches some level of wage at which, even though nobody is using the advanced technology, the richest agent in the economy will be able to get credit. From this moment, the bad equilibrium $(\lambda=0)$ disappears. The unique equilibrium will be given by $\lambda=\lambda_{\max }$. Theorem 4 formalizes this statement.

Theorem 4 . If Assumptions 3 and 4 are satisfied, there exist two wage levels, $v_{1}$ and $v_{2}$, with $v_{1}<v_{2}$, such that:

$$
c_{R}\left(1, v_{1}, 1\right)=c_{R}\left(0, v_{2}, 1\right)=\beta
$$

Then:

(i) For any $v<v_{1}$, there exists only one equilibrium.

(ii) For some $v \in\left(v_{1}, v_{2}\right)$, there are multiple equilibria.

(iii) For some $v>v_{2}$, there exists only one equilibrium.

Proof. [See Appendix].

In Figure 4, we show the evolution of the equilibria in the economy. For a given $v$, we can denote by $\lambda_{m}(v)$ and $\lambda_{M}(v)$ the lowest and the highest fixed points of equation (15), and by $R(v)$ the total resources per project in the economy. We see that $R(v)$ is always lower than $\lambda_{M}(v)$, which implies that $\lambda_{M}(v)$ will never be an equilibrium and that $\lambda_{m}(v)$ is decreasing. See Appendix for a formal proof of these statements. 
[Figure 4 here]

Note that if we had a small open economy with perfect capital mobility, the highest fixed point, $\lambda_{M}(v)$, would be attainable. The implication of this is that an open economy will be expected to grow faster than a closed economy. Moreover, we should observe a higher variability for open economies than for closed ones.

Obviously, the variability in the economy during the multiple equilibrium stage will be higher than the variability in other stages. The degree of variability will depend on the sunspot probabilistic distribution. Since the equilibrium value of $\lambda$ is perfectly correlated with the sunspot, which is a random variable, $\lambda$ is a random variable itself. In that sense, in this economy we can use the variance of $\lambda$ as a proxy for variability. The behavior of the variance of $\lambda$ is such that, when the multiplicity appears, the variance jumps from zero to a positive value. Then, the variance will be, first, decreasing with respect to $v$, then starting to rise as the size of the economy increases. When the multiplicity disappears, the variance will be zero again. The reason for this behavior is that if two equilibria are close and one of them starts moving toward a third one, the variability decreases until they become too close. This is formalized in the next proposition.

Proposition 5 . In the multiple equilibria stage, the variability of the output first decreases and then increases.

Proof. [See Appendix].

In order to prove Proposition 5, we use a time-invariant probability distribution in which each sunspot has the same probability each period. The results are the same if we use symmetric first-order Markov probabilities in which the probability of observing a given sunspot this period will depend on the sunspot observed last period. The results are not robust to all non-symmetric Markov probabilities or other time-depending probabilities. 


\subsection{Wages, Interest Rates and Entrepreneurship}

In this subsection, we will study the equilibrium values of wages, interest rates, and measure of entrepreneurs during the development process. We will prove that, if an economy satisfies two conditions for growth, then, for any initial condition $v_{0}$, the economy will converge to the long run equilibrium with positive probability. The conditions for growth imply that there exists a minimum required level of productivity in the subsistence technology, and that the set of sunspots that implies the "good" equilibrium with probability zero has measure zero.

The conditions for growth are the following:

$$
g_{l}(\delta)>w^{\prime} \text { and } m(A)>0
$$

where $m(A)$ is the measure of a set $A$, and $A=\left\{\sigma_{t}: \operatorname{Pr}\left[\lambda\left(\sigma_{t}\right)=R\left(v_{t}\right)\right]>0\right\}$. The first condition guarantees that the economy will reach the multiple equilibria stage. The second implies that the economy will leave that stage.

If the conditions for growth are satisfied, the economy will reach the multiple equilibria stage and, with positive probability, will be at the highest equilibrium. We can construct a sequence of $\lambda_{t}$ from $t$ equals one to $T$, in which $\lambda_{T}$ takes the highest value. This sequence has a positive probability if $T<\infty$. Since $\lambda_{t}$ is increasing at some finite rate, the economy will leave this stage and will converge to the long run equilibrium: $\lambda^{*}=1, r^{*}=1$ and $v^{*}=f_{l}\left(\delta, \lambda^{*}\right)$. This fact is proved in the next theorem.

Theorem 6 . If the condition for growth is satisfied, for any initial $v_{0}$, the economy will converge to the long run equilibrium with positive probability.

Proof. [See Appendix]. 


\subsection{Credit Market and Variability}

The purpose of this subsection is to analyze how different degrees of imperfection in the credit market will affect the equilibrium of the economy. In Subsection 5.1, we have already seen that, when there exist imperfections in the credit market (i.e. $0<\theta<1$ ), we could have multiple equilibria. Now, we show that when the credit market is perfect, i.e. $\theta=1$, or when the credit market does not exist, i.e. $\theta=0$, the equilibrium will be unique. The reason for this is that, when there is no credit market, there is no interaction between the externality in the productive sector and the borrowing constraint. Only the fraction of people with wealth greater than the entry cost will become entrepreneurs. Also, when the credit market is perfect, there are no longer borrowing constraints and, therefore, all the resources are used to finance the payment of the entry cost of those who want to use the advanced technology. The interest rate will be such that the agents are indifferent between using the advanced or the subsistence technology. Subsubsections 5.3.1 and 5.3.2 will study both cases.

\subsubsection{Perfect-Credit Market Economy}

Suppose that $v_{0}<\frac{\phi}{\delta}$. This condition means that the initial resources are not enough to finance all the people in this economy. The fraction of people who become managers in the advanced technology sector is given by $\lambda_{0}=\frac{\delta v_{0}}{\phi}$. Since, by assumption, it is profitable to be a manager when the interest rate is one, everybody will demand credit for investment. In order for the credit market to clear, the interest rate will have to rise.

Once we have $\lambda_{0}$, the wage rate for the next period, $v_{1}$, can be uniquely determined using $v_{1}=v(\lambda)$ (see Section 4). Notice that, even though we have an externality in the productive sector, each time the measure of entrepreneurs is only determined by the resource constraints in the economy. The next proposition formalizes this 
statement.

Proposition 7 . Given some endowment $\mathrm{cv}_{0}$ for the initial old people such that $v_{0}<\frac{\phi}{\delta}$, if the credit market is perfect, then:

(i) At each $t$, there is only one equilibrium, i.e. $v_{t}, \lambda_{t+1}$, and $r_{t, t+1}$ are uniquely determined.

(ii) The equilibrium sequences $\left\{v_{t}\right\}$ and $\left\{\lambda_{t}\right\}$ are non decreasing and converge to the long run equilibrium.

Proof. [See Appendix].

It is worthwhile to notice the behavior of the interest rate. When $\lambda<1, r_{t, t+1}(\lambda)$ is increasing in $\lambda$. The reason for this is that, as the total fraction of managers increases in this economy, the managerial profits also increase (due to the externality). As a result, the interest rate needed to clear this market is higher. However, as soon as $\lambda$ reaches the value of one, the financial resources are abundant relative to the population resources (the fraction of managers can not be greater than one) and the interest rate will drop abruptly to one (the storage technology return). Notice that we can observe the same situation when there exist multiple equilibria. In that case, the drastic change in interest rate will be accompanied by a drastic change in $\lambda$. However, when the credit market is perfect, a drastic change in interest rate will be caused by a change of regime. The economy moves from a resource-constrained economy to a resource-unconstrained economy. In this case, a large movement in the interest rate is accompanied by a small change in $\lambda$.

\subsubsection{Non Credit Market Economy}

Suppose now that the initial condition over $v_{0}$ is such that $\beta v_{0}<\phi$, which implies that nobody will become an entrepreneur in period one. The wage rate in that period will be given by $v_{1}=g_{l}(\delta)$. In this case, the condition for growth is that $v_{1}>\frac{\phi}{\beta}$; 
otherwise the advanced technology will never be used. Notice that, when there is no credit market or when the credit market is incomplete, there are some conditions on the productivity of the subsistence sector (see Subsection 5.2) to guarantee that the economy will take off. This is not the case when the credit market is perfect.

Since people cannot borrow, the entry cost must be self-financed. Then, given $v_{t}$, only a fraction of people equal to $1-H\left(\frac{\phi}{v_{t}}\right)$ will become managers in the next period. Once $\lambda_{t-1}$ is known, the wage rate $v_{t+1}$ can be easily determined (see Section 4). Then the sequences of wages $\left\{v_{t}\right\}$ and measures of managers $\left\{\lambda_{t}\right\}$ are uniquely determined, and they will converge to the long-run equilibrium. The next proposition formalizes this statement.

Proposition 8 . Given some endowment $\mathrm{cv}_{0}$ for the initial old people such that $v_{0}<\frac{\phi}{\beta}$, if the credit market does not exist and $g_{l}(\delta)>\frac{\phi}{\beta}$, then:

(i) At each period $t$, there is only one equilibrium, i.e. $v_{t}$ and $\lambda_{t+1}$ are uniquely determined.

(ii) The equilibrium sequences $\left\{v_{t}\right\}$ and $\left\{\lambda_{t}\right\}$ are non decreasing and converge to the long run equilibrium.

Proof. [See Appendix].

\section{Conclusion}

This paper explains the GDP variability pattern of an economy during the development process. We show that, at the middle stages of development, the economy experiences high levels of GDP variability. On the other hand, in early and mature stages of development, we observe a much lower variability in per capita GDP. This variability is explained because, in an imperfect credit market environment, the number of equilibria will depend on the size of the economy. In particular, when the economy is very poor, there is only one possible equilibrium. After the economy 
reaches some threshold level, there can be multiple equilibria. This multiplicity disappears when the economy is fully developed. The existence of multiple equilibria is due to the fact that the externality in the productive sector will be reflected in the financial one. A larger fraction of people using the advanced technology will imply a larger fraction of people with access to the credit market.

The relationship between the degree of development of the financial sector and the variability in the economy is also analyzed. We show that, in the case of either economies with perfect credit markets or economies in which the credit markets are non-existent, the equilibrium is unique. However, when the credit market exists but is imperfect, there could be more than one equilibrium. In the latter case, the multiplicity arises in the middle stages of development. This is due to the fact that when there is no credit market, there is no interaction between the externality in the productive sector and the borrowing constraint. Only the fraction of people with wealth greater than the entry cost will become entrepreneurs. Also, when the credit market is perfect, there are no borrowing constraints, and all the resources are used to finance the payment of the entry cost for those who want to use the advanced technology.

\section{APPENDIX}

Proof of Proposition 1: First of all, we need to prove that $\Pi_{a}(\lambda)$ is a continuous function of $\lambda$.

Claim: $\Pi_{a}(\lambda)$ is a continuous and increasing function of $\lambda$.

Proof. In order to prove this claim, we need to use a result that will be proved later (Proposition 2): $v(\lambda)$ is a continuous and increasing function of $\lambda$. Given that $f(l, \lambda)-v(\lambda) l$ is bounded from above, continuous in $l$ and $\lambda$, and with compact range, we can apply the Theorem of the Maximum to show that $\Pi_{a}(\lambda)$ is a continuous function. To see that it is increasing in $\lambda$, just take derivatives with respect to $\lambda$ and applying the Envelope Theorem we get: 


$$
\frac{\partial \Pi(\lambda)}{\partial \lambda}=f_{\lambda}-\frac{\partial v(\lambda)}{\partial \lambda} l(v(\lambda), \lambda)
$$

This is positive if the average labor productivity is greater than the marginal labor productivity, which is the present case (see Proposition 2).

(i) By our claim, it is easy to see that $c_{R}(\cdot)$ is continuous in $\lambda, r$, and $v$.

(ii) Moreover, we can take partial derivatives with respect to $r$, and we get:

$$
\frac{\partial c_{R}(\cdot)}{\partial r_{t, t+1}}=\frac{\theta \Pi_{a}(\lambda)}{v_{t}\left(r_{t, t+1}\right)^{2}}>0
$$

(iii) Now, taking derivatives with respect to $\lambda$ and $v$, respectively:

$$
\begin{gathered}
\frac{\partial c_{R}(\cdot)}{\partial v_{t}}=\frac{-c_{R}(\cdot)}{v_{t}}<0 \\
\frac{\partial c_{R}(\cdot)}{\partial \lambda}=\frac{-\theta}{v_{t} r_{t, t+1}}\left(\frac{\partial \Pi_{a}(\lambda)}{\partial \lambda}\right)<0
\end{gathered}
$$

Q.E.D.

Proof of Proposition 2: Given that all the conditions are satisfied for the Theorem of the Maximum, we can apply it to equations (5) and (6). After maximizing, we get the following equations:

$$
\begin{gathered}
f_{l}\left(l_{a}(v, \lambda), \lambda\right)=v \\
g_{l}\left(l_{s}(v)\right)=v
\end{gathered}
$$

Now, using the equilibrium market condition (14), we have a system of three equations with three unknowns: $l_{a}(\lambda, \delta), l_{s}(\lambda, \delta)$ and $v(\lambda, \delta)$. This can be reduced to a system of two equations (solving for $l_{s}(\lambda, \delta)$ ). Taking derivatives with respect to $\lambda$, we get:

$$
\left(\begin{array}{cc}
-1 & f_{l l} \\
-1 & -g_{l l} \frac{\lambda}{(1-\lambda)}
\end{array}\right)\left(\begin{array}{c}
\frac{\partial v}{\partial \lambda} \\
\frac{\partial l_{a}}{\partial \lambda}
\end{array}\right)=\left(\begin{array}{c}
-f_{l \lambda} \\
-g_{l l} \frac{\delta-l_{a}}{(1-\lambda)^{2}}
\end{array}\right)
$$

Solving (30), we have:

$$
\left(\begin{array}{c}
\frac{\partial v}{\partial \lambda} \\
\frac{\partial l_{a}}{\partial \lambda}
\end{array}\right)=\frac{1}{|A|}\left(\begin{array}{c}
-f_{l \lambda} g_{l l} \frac{\lambda}{1-\lambda}-f_{l l} g_{l l} \frac{\delta-l_{a}}{(1-\lambda)^{2}} \\
f_{l \lambda}-g_{l l} \frac{\delta-l_{a}}{(1-\lambda)^{2}}
\end{array}\right)
$$


Where $|A|=-\left(f_{l l}+g_{l l} \frac{\lambda}{(1-\lambda)}\right)$. Notice that since it must be the case that for any $(v, \lambda)$ when $\lambda>0, l_{a}>l_{s}$, then $l_{a}>\delta$. Therefore, it is easy to see that $\frac{\partial v}{\partial \lambda}>0$. Moreover, if the externality effect is strong enough, i.e. if $f_{l \lambda}$ is large enough, then $l_{a}$ will also be increasing.

Now, it follows from (6) that $l_{s}(v)$ is a decreasing function of $v$, and since $v$ is an increasing function of $\lambda$, it must be the case that $l_{s}$ is a decreasing funtion of $\lambda$. Q.E.D.

\section{Proof of Proposition 3:}

(i) The continuity of $\gamma(\cdot)$ follows from the continuity of $H(\cdot)$ and the continuity of $c_{R}(\cdot)$.

(ii) Since $c_{R}(\cdot)$ is decreasing in $\lambda$ and $v$, and $H(\cdot)$ is increasing in $c$, this proves that $\gamma(\cdot)$ is increasing in $\lambda$ and $v$.

(iii) To prove that $\gamma(\cdot)$ is decreasing in $r$, just note that $c_{R}(\cdot)$ is increasing in $r$ and $H(\cdot)$ is increasing in $c$.

(iv) Taking derivatives with respect to $\gamma(\cdot)$ :

$$
\frac{\partial \gamma(\cdot)}{\partial \lambda}=-h\left(c_{R}(\lambda, v, r)\right) \frac{\partial c_{R}(\lambda, v, r)}{\partial \lambda}>0
$$

Equation (32) is positive because of Proposition 1 part (iii). Q.E.D.

\section{Proof of Theorem 4:}

(i) For any $v<v_{1}$, we have that $c_{R}(1, v, 1)>\beta$. Then $\gamma(\lambda, v, 1)=0$ for any $\lambda$. The only equilibrium is $\lambda=0$.

(ii) Because of (23) and the continuity of $c_{R}(\cdot)$, we can define a function $\lambda^{z}(v)$ for $v \in\left(v_{1}, v_{2}\right)$ such that:

$$
c_{R}\left(\lambda^{z}(v), v, 1\right)=\beta
$$

Notice that $\lambda^{z}(\cdot)$ is decreasing in $v, \gamma_{\lambda}(\cdot)=0$ for $\lambda \leq \lambda^{z}(v)$, and $\gamma_{\lambda}(\cdot)>0$ for $\lambda>\lambda^{z}(v)$. Notice also that, for $\lambda \in\left(\lambda^{z}(v), \beta\right), \gamma_{\lambda \lambda}<0$. Since $h(\cdot)$ and $\frac{\partial c_{R}(\cdot)}{\partial \lambda}$ are continuous functions, we can have $v^{\prime}$ and $\lambda^{\prime}$ such that:

$$
\lambda^{\prime}=\gamma\left(\lambda^{\prime}, v^{\prime}, 1\right) \text { and } \gamma_{\lambda}\left(\lambda^{\prime}, v^{\prime}, 1\right)=1
$$

Assuming that $c_{R}\left(1, v_{2}, 1\right)>\alpha$ (we can pick $\alpha$ close enough to zero), we can define two functions: $\lambda_{m}:\left[v^{\prime}, v_{2}\right] \rightarrow\left[0, \lambda^{\prime}\right]$ and $\lambda_{M}:\left[v^{\prime}, v_{2}\right] \rightarrow\left[\lambda^{\prime}, \lambda^{\prime \prime}\right]$, such that:

$$
\lambda_{j}(v)=\gamma\left(\lambda_{j}(v), v, 1\right) \text { for } j=m, M
$$


Claim: The functions in equation (35) exist and are well defined. Proof. Note that for any $v \in\left(v^{\prime}, v_{2}\right): \lambda^{z}(v)>\gamma\left(\lambda^{z}(v), v, 1\right) ; \gamma\left(\lambda^{\prime}, v, 1\right)>\lambda^{\prime}$ and $\gamma(1, v, 1)<1$. Then, due to the continuity of $\gamma$, for each $v$, there exist two functions $\lambda_{m}$ and $\lambda_{M}$, such that they are the fixed points of equation (35). Moreover, $\lambda_{m}(v) \in\left(\lambda^{z}(v), \lambda^{\prime}\right)$, and $\lambda_{M} \in\left(\lambda^{\prime}, 1\right)$.

Claim: $\lambda_{m}(v)$ is a decreasing function and $\lambda_{M}(v)$ is an increasing function. Proof. For $\lambda_{m}(v)$, suppose not. Take $w_{1}<w_{2}$. Then, for any $\lambda \in\left(\lambda_{m}(v), \lambda^{\prime}\right)$, $\gamma\left(\lambda, w_{1}, 1\right)>\lambda$. But, $\gamma\left(\lambda_{m}\left(w_{2}\right), w_{2}, 1\right)>\gamma\left(\lambda_{m}\left(w_{2}\right), w_{1}, 1\right)>\lambda_{m}\left(w_{2}\right)$. A contradiction.

For $\lambda_{M}(v)$, suppose not. Take $w_{1}<w_{2}$. Then, for any $\lambda \in\left(\lambda^{\prime}, \lambda_{M}(v)\right)$, $\gamma\left(\lambda, w_{1}, 1\right)>\lambda$. But, $\gamma\left(\lambda_{M}\left(w_{2}\right), w_{2}, 1\right)>\gamma\left(\lambda_{M}\left(w_{2}\right), w_{1}, 1\right)>\lambda_{M}\left(w_{2}\right)$. A contradiction.

Those fixed points will be equilibria if and only if $\lambda_{j}(v)<R(v)$, where we can define $R(v)$ as:

$$
R(v)=\frac{\delta v}{\phi}
$$

Assume that $v^{\prime}$ is such that $\lambda^{\prime}>\frac{\delta v^{\prime}}{\phi}$. Then, at $v^{\prime}$, the only equilibrium is given by $\lambda=0$. Since $\lambda_{m}(v)$ is decreasing, $R(v)$ is increasing and $R\left(v_{2}\right)>\lambda_{m}\left(v_{2}\right)=0$, then, there exists a level of wage $w^{\prime}$ such that $R\left(w^{\prime}\right)=\lambda_{m}\left(w^{\prime}\right)$. At $w^{\prime}$, there are two equilibria: $\lambda=0$ and $\lambda=R\left(w^{\prime}\right)=\lambda_{m}\left(w^{\prime}\right)$.

For any $v \in\left(w^{\prime}, v_{2}\right)$ there are three equilibria: $\lambda=0, \lambda=\lambda_{m}\left(w^{\prime}\right)$, and $\lambda=$ $\min \left\{R(v), \lambda_{M}(v)\right\}$. The first two equilibria are obvious. We need to show that the third equilibrium exists. Then, we will show that for any $v \leq v_{2}, R(v)<\lambda_{M}(v)$. First, suppose that $R(v)<\lambda_{M}(v)$. Then, $\lambda_{M}(v)$ is not an equilibrium. Since $\gamma(R(v), v, 1)>R(v)$, there exists $r=r_{0}(R(v))$ such that $\gamma\left(R(v), v, r_{0}(R(v))\right)=$ $R(v)$. The continuity of $\gamma(\cdot)$ guarantees the existence of such interest rate. See Section 4 for a proper definition of $r_{0}(R(v))$. Now, suppose that $\lambda_{M}(v)<R(v)$. Then, by definition, $\lambda_{M}(v)$ is an equilibrium. Since $\gamma(R(v), v, 1)<R(v)$, then $R(v)$ can not be an equilibrium. Note that, at $v=v_{2}, \lambda_{m}\left(v_{2}\right)=0$. That means that at $v=v_{2}$, there are only two equilibria.

It is easy to see that, in fact, $R(v)<\lambda_{M}(v)$ for all $v<v_{2}$. First, define $v^{\prime \prime}$ as: $c_{R}\left(1, v^{\prime \prime}, 1\right)=\alpha$. It is trivial to show that $v^{\prime \prime}>v_{2}$. Then, we can extend the domain of the function $\lambda_{M}(v)$ from $\left[v^{\prime}, v_{2}\right]$ to $\left[v^{\prime}, v^{\prime \prime}\right]$. Obviously, $\lambda_{M}\left(v^{\prime \prime}\right)=1$ and $R\left(v^{\prime \prime}\right)<1$. Now, since $\lambda_{M}(v)$ and $R(v)$ are both increasing and (weakly) concave 
functions, then:

$$
R(v)<\lambda_{M}(v) \text { for all } v \in\left(v^{\prime}, v^{\prime \prime}\right)
$$

(iii) First, note that for some $v^{\prime \prime \prime}>v_{2}, \gamma\left(0, v^{\prime \prime \prime}, 1\right)>0$. Then, for any $v>v^{\prime \prime \prime}$, the bad equilibrium vanishes from the economy. Now, since we have proved in (ii) that $R(v)<\lambda_{M}(v)$, then the only equilibrium in this stage will be given by: $\lambda_{t}=\frac{\delta v_{t}}{\phi}$ and $r_{t, t+1}=r_{0}\left(\frac{\delta v_{t}}{\phi}\right)$. Note that when $v=\frac{\phi}{\delta}, \lambda_{t}=1$ and $r_{t, t+1}=1$, for all $t$. Q.E.D.

Proof of Proposition 5: Let us denote by $\Pi_{g}$ and $\Pi_{b}$, the probabilities of choosing the good and the bad equilibrium, respectively, with $\Pi_{g}+\Pi_{b}<1$. Then, the variance of the equilibrium value, for a given $v \in\left(w^{\prime}, v_{2}\right)$, is given by the next equation:

$$
\begin{gathered}
V(\lambda(v))=\left(1-\Pi_{g}-\Pi_{b}\right)\left(\Pi_{g}+\Pi_{b}\right)\left(\lambda_{m}(v)\right)^{2}+\left(1-\Pi_{g}\right) \Pi_{g}(R(v))^{2} \\
-2\left(1-\Pi_{g}-\Pi_{b}\right) \Pi_{g} \lambda_{m} R(v)
\end{gathered}
$$

When $v$ is close to $w^{\prime}$, taking derivatives and assuming, for simplicity, that $\Pi_{g}=$ $1-\Pi_{g}-\Pi_{b}$, we have that:

$$
\frac{\partial V(\lambda(v))}{\partial v} \cong 2 \Pi\left(1-\Pi-\Pi \frac{\delta w^{\prime}}{\phi}\right)\left(\frac{\delta}{\phi}+\frac{\partial \lambda_{m}(v)}{\partial v}\right)<0
$$

This is true since it can be showed that $\frac{\partial \lambda_{m}(v)}{\partial v} \rightarrow-\infty$ as $v \rightarrow w^{\prime}$. Now, if $v$ is close to $v_{2}$, and noting that $\frac{\partial \lambda_{m}(v)}{\partial v} \rightarrow 0$ as $v \rightarrow v_{2}$, we have that:

$$
\frac{\partial V(\lambda(v))}{\partial v} \cong 2 \Pi(1-\Pi) \frac{\delta}{\phi}>0
$$

Q.E.D.

Proof of Theorem 6: Assume, without loss of generality, that $v_{0}<w^{\prime}$. Then $\lambda_{1}=0$. Since $g_{l}(\delta)>w^{\prime}$, then with positive probability $\lambda_{2}=\frac{\delta v_{1}}{\phi}>\lambda_{1}=0$. By induction, we can construct increasing sequences for $\lambda_{t}$ and $v_{t}$, with positive probability. Since $l_{s}(\lambda)$ is decreasing in $\lambda, g_{l}\left(l_{s}\right)$ is decreasing in $l_{s}$, and $g_{l}(\varepsilon) \rightarrow \infty$ as $\varepsilon \rightarrow 0$, at some point $\tau$, given $\lambda_{\tau}, v_{\tau} \geq \frac{\phi}{\delta}$. If such $\lambda_{\tau}$ exists with positive probability, then $\lambda_{\tau+1}=1$ with the same probability. Once the economy reaches this stage, for all $t \geq \tau+1, \lambda_{\tau}=1=\lambda^{*}$ and $v_{t}=f_{l}(\delta, 1)=v^{*}$. At this point, $r_{t, t+1}=1$. 
The behavior of the interest rate is as follows. If $\lambda_{t+1}=R\left(v_{t}\right)$, then $r_{t, t+1}=$ $r_{0}\left(R\left(v_{t}\right)\right)$. If $\lambda_{t+1}<R\left(v_{t}\right)$, then $r_{t, t+1}=1$. If $R\left(v_{t}\right)>1$, then $\lambda_{t+1}=1$ and $r_{t, t+1}=1$. Q.E.D.

\section{Proof of Proposition 7:}

(i) Just note that the equilibrium will be given by: $\lambda_{t+1}=\max \left\{\frac{\delta v_{t}}{\phi}\right\} ; r_{t, t+1}=$ $r_{l}\left(\frac{\delta v_{t}}{\phi}\right)$ if $\frac{\delta v_{t}}{\phi}<1$ and $r_{t, t+1}=1$ if $\frac{\delta v_{t}}{\phi} \geq 1$; and $v_{t+1}=f_{l}\left(l_{a}\left(\frac{\delta v_{t}}{\phi}\right), \frac{\delta v_{t}}{\phi}\right)$. All the variables depend on just $v_{t}$.

(ii) Assume, without loss of generality, that $v_{0}=0$. Then, since $v_{1}>v_{0}$, we have $\lambda_{2}>\lambda_{1}$. We can continue this reasoning by induction. If $v_{t-1}<v_{t}<\frac{\delta}{\phi}$, then $\lambda_{t}<\lambda_{t+1}$. Since $l_{s}(\lambda)$ is decreasing in $\lambda, g_{l}\left(l_{s}(\lambda)\right)$ is decreasing in $l_{s}$, and $g_{l}(\varepsilon) \rightarrow \infty$ as $\varepsilon \rightarrow 0$, at some point $\tau v_{t} \geq \frac{\delta}{\phi}$. Then, $\lambda_{t+1}=1$ and $v_{t+1}=f_{l}(\delta, 1)$. Then, for any $t \geq \tau+1, \lambda_{t}=\lambda^{*}$ and $v_{t}=v^{*}$. Notice that $r_{t, t+1}=r_{l}\left(\frac{\delta v_{t}}{\phi}\right)$ is strictly increasing when $v_{t}<\frac{\delta}{\phi}$. To prove this, just note that $\frac{\partial \Pi_{a}(\lambda)}{\partial \lambda}>0$ and $\frac{\partial \Pi_{s}(\lambda)}{\partial \lambda}<0$. When $v_{t}>\frac{\delta}{\phi}$, $r_{t, t+1}=1$. This drastic change in the interest rate is associated to a change in the regime: from a constrained to an unconstrained economy. Q.E.D.

\section{Proof of Proposition 8:}

(i) Since, by assumption, $f(l, 0)-\phi>g(l)$ for all $l$; all the agents with wealth greater than $\phi$ (i.e. with ability greater than $\frac{\phi}{v_{t}}$ ) will pay the entry cost at $t$ and become entrepreneurs at $t+1$. Then:

$$
\lambda_{t+1}=1-H\left(\frac{\phi}{v_{t}}\right)
$$

Given $\lambda_{t+1}$, then $v_{t+1}=v\left(\lambda_{t+1}\right)$, where $v(\lambda)$ is the function defined in Proposition 2 .

(ii) Note that, in equation (41), $\lambda_{t+1}$ is an increasing function of $v_{t}$. Also, $v(\lambda)$ is an increasing function of $\lambda$. Given the condition for growth in this economy, $v_{1}=g_{l}(\delta)>\frac{\phi}{\beta}$. Then, $\lambda_{2}=1-H\left(\frac{\phi}{g_{l}(\delta)}\right)>\lambda_{1}=0$. Following by induction, we can establish increasing sequences for $\lambda_{t}$ and $v_{t}$ when $v_{t}<\frac{\phi}{\alpha}$. Since $l_{s}(\lambda)$ is decreasing and $g_{l}(\varepsilon) \rightarrow \infty$ as $\varepsilon \rightarrow 0$, there exists some finite $\tau$ at which $v_{t} \geq \frac{\phi}{\alpha}$. From then on, $\lambda_{t}=1=\lambda^{*}$, for all $t$, and $v_{t}=f_{l}(\delta, 1)=v^{*}$, for all $t$. Q.E.D.

\section{REFERENCES}

Acemoglu, D. and F. Zilibotti (1997), Was Prometheus Unbound by Chance? Risk, Diversification and Growth, Journal of Political Economy, vol. 105, No. 4, pp. 709-751. 
Aghion, P., A. Banerjee and T. Piketty (1999), Dualism and Macroeconomic Volatility, Quarterly Journal of Economics, vol. 114 (4), pp. 1359-1397.

Arrow, K. (1962), The Economic Implications of Learning by Doing, Review of Economic Studies, vol. 29, pp. 155-173.

Aumann, R. (1987), Correlated Equilibrium as an Expression of Bayesian Rationality, Econometrica, vol. 55, pp. 1-18.

Banerje, A.V. and A.F. Newman (1993), Occupational Choice and the Process of Development, Journal of Political Economy, vol. 101, pp. 274-298.

Bencivenga, V. and B. Smith (1991), Financial Intermediation and Endogenous Growth, Review of Economic Studies, vol.58, pp. 195-209.

Carranza, L. (1995), Credit Imperfections, Inequality and Economic Growth, Center for Economic Research Discussion Paper No. 286, University of Minnesota.

Chari, V.V., P. Kehoe and E. McGrattan (1996), Poverty of Nations: A Quantitative Exploration, NBER Working Paper, No. 5414.

Cooper, R. and J. Ejarque (1995), Financial Intermediation and the Great Depression: A Multiple Equilibrium Interpretation, Carnegie-Rochester Conference Series on Public Policy, vol. 43, pp. 285-324.

De Long, J. and L. Summers (1984), The Changing Cyclical Variability of Economic Activity in the United States, NBER Working Paper No. 1450.

Enciclopædia Britannica (1999).

Galor, O. and J. Zeira (1993), Income Distribution and Macroeconomics, Review of Economic Studies, vol. 60, pp. 35-52.

Hansen, G.D. (1986), Growth and Fluctuations, Working Paper, University of California, Santa Barbara.

Härdle, W. (1990), Applied Nonparametric Regression. Econometric Society Monographs. Cambridge University Press.

Levine, R. (1997), Financial Development and Economic Growth: Views and Agenda, Journal of Economic Literature, vol. 35, pp. 688-726.

Lucas, R. (1988), On the Mechanics of Economic Development, Journal of Monetary Economics, vol. 22, pp. 3-42.

McGrattan, E. and J. Schmitz (1998), Explaining Cross-Country Income Differences, Federal Reserve Bank of Minneapolis, Staff Report No. 250.

Mendoza, E. (1995), The Terms of Trade, the Real Exchange Rate, and Economic Fluctuations, International Economic Review, vol. 36, No. 1pp. 101-137. 
Parente, S. and E. Prescott (1994), Barriers to Technology Adoption and Development, Journal of Political Economy, vol. 102, pp. 298-321.

Quah, D. (1993), Empirical Cross-section Dynamics in Economic Growth, European Economic Review, vol.37, pp. 426-434.

Ramey, G. and V. Ramey (1995), Cross-Country Evidence on the Link Between Volatility and Growth, American Economic Review, vol. 85, No. 5, pp. 1138-1151.

Romer, C. (1986), Is the Stabilization of the Postwar Economy a Figment of the Data?, American Economic Review, vol. 76, pp. 314-334.

Romer, P. M. (1986), Increasing Returns and Long-Run Growth, Journal of Political Economy, vol. 94, No. 5, pp. 1002-1037.

Sorger, G. (1994), On the Structure of Ramsey Equilibrium: Cycles, Indeterminacy, and Sunspots, Economic Theory, vol. 4, pp. 745-764.

Spear, S. (1991), Growth, Externalities, and Sunspots, Journal of Economic Theory, vol. 54, pp. 215-223.

Summers, A. and R. Heston (1991), The Penn World Table (Mark 5): An Expanded Set of International Comparisons, 1950-1988, Quarterly Journal of Economics, vol. 106, pp. 327-368. 


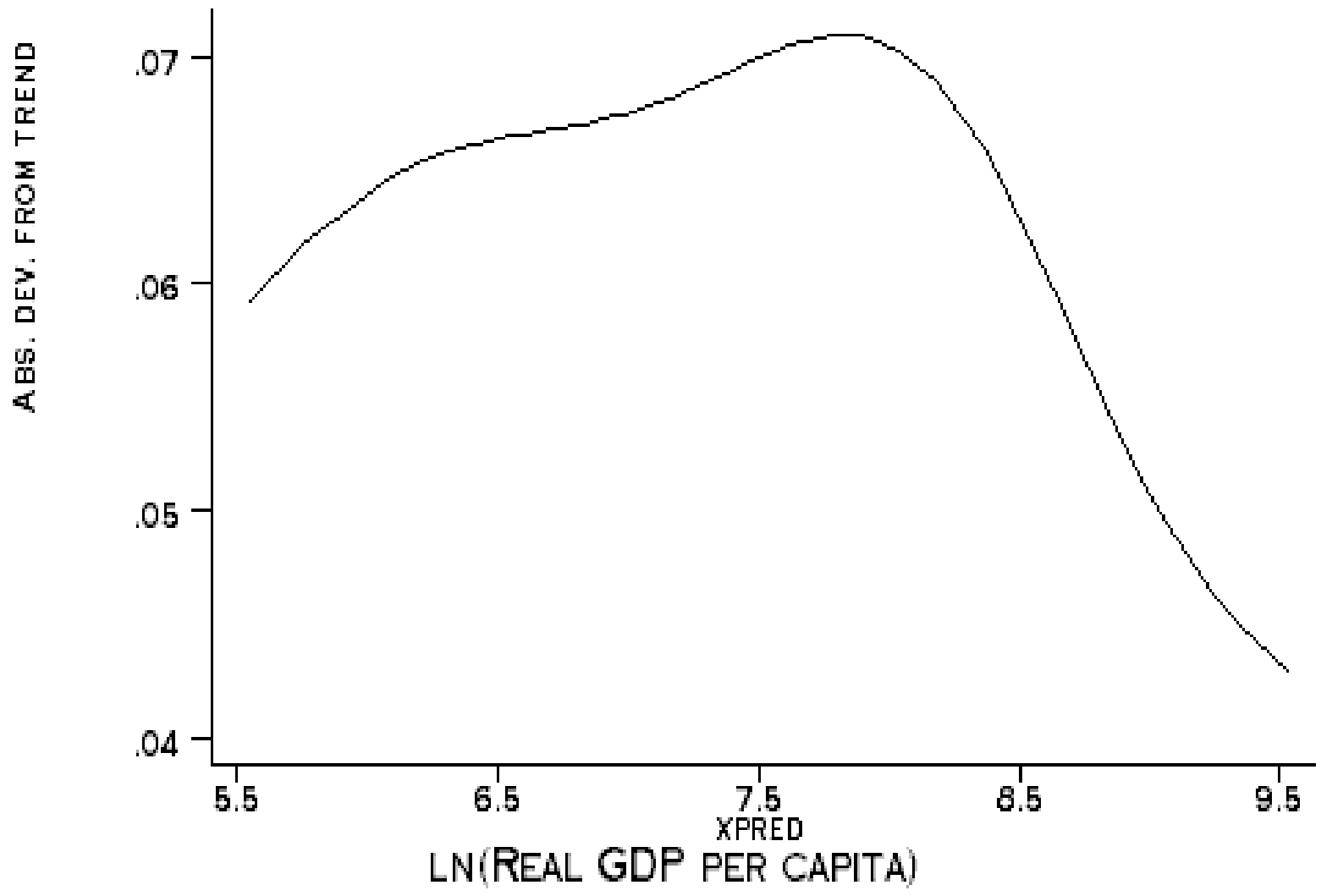

Figure 1: Kernel estimation of the conditional mean 

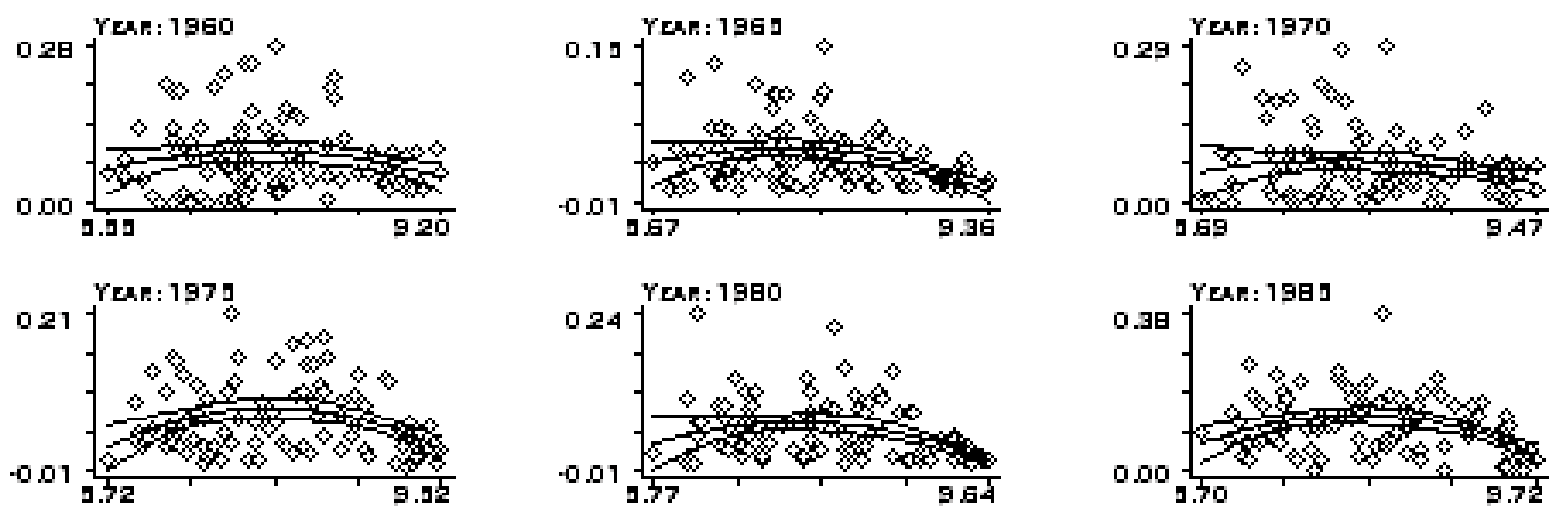

Figure 2: Absolute deviation from trend vs. $\ln ($ Real GDP per capita) 


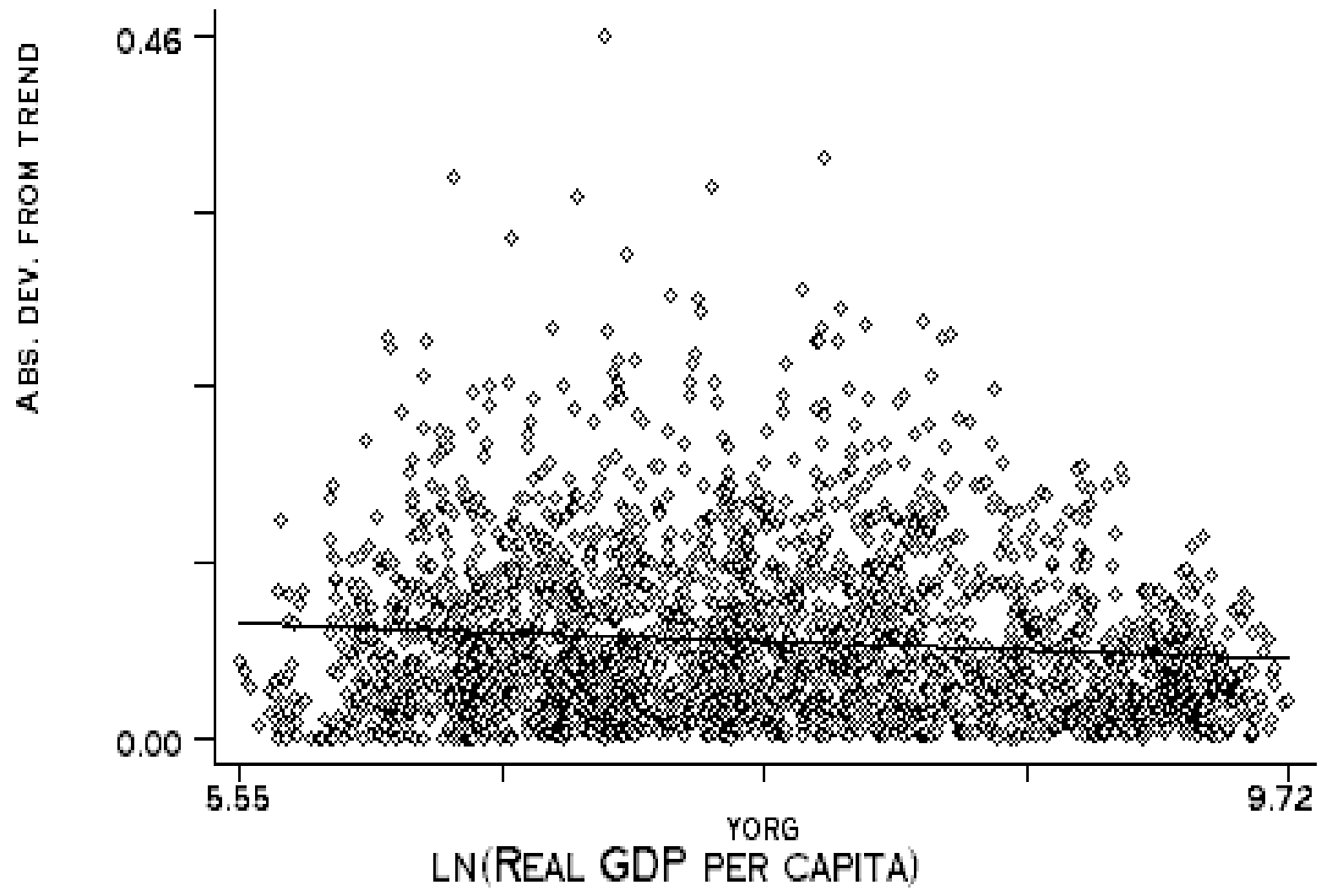

Figure 3: Linear adjustment of the pooled sample 


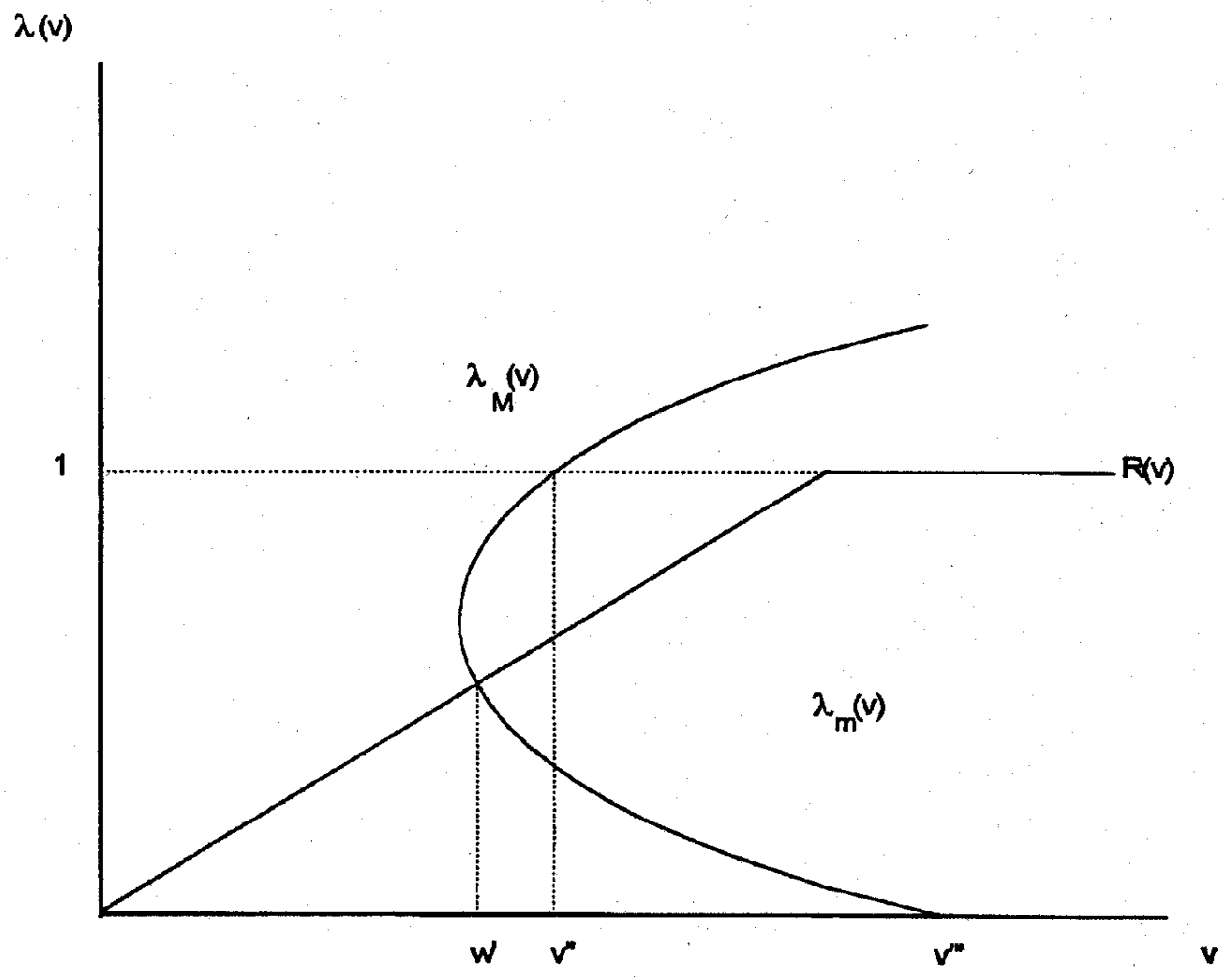

Figure 4: Multiplicity of equilibria. 